\title{
モモ果実香気成分の界面前進凍結濃縮
}

\author{
飛塚幸喜 ${ }^{1, \dagger}$, 安食雄介 ${ }^{1}$, 野内義之 ${ }^{1}$, 宮脇長人 ${ }^{2}$ \\ ${ }^{1}$ 山形県工業技術センター, ${ }^{2}$ 石川県立大学
}

\section{Progressive Freeze-concentration of Aroma Components of Peach Fruits}

\author{
Koki TOBITSUKA $^{1, \dagger}$, Yusuke AJIKI ${ }^{1}$, Yoshiyuki NOUCHI ${ }^{1}$, and Osato MIYAWAKI ${ }^{2}$ \\ ${ }^{1}$ Yamagata Research Institute of Technology, 2-2-1 Matsuei, Yamagata, Yamagata 990-2473, Japan \\ ${ }^{2}$ Ishikawa Prefectural University, 1-308 Suematsu, Nonoichi-Machi, Ishikawa 921-8836, Japan
}

\begin{abstract}
Because it does not involve heating, "freeze-concentration" is one of the most suitable methods for concentrating thermally unstable materials, for instance, aroma components. We, therefore, tried to prepare a concentrate of the aroma components of peach fruits by progressive freeze-concentration. Condensated water containing the aroma components of peach fruits was obtained by vacuum distillation of fresh juice using a rotary evaporator, and was further concentrated by progressive freeze-concentration. When the distillation-condensate was concentrated 11.6 times (volume to volume) by the progressive freeze-concentration, the major aroma components of peach fruits ( $\gamma$-decanolactone, $(E)$-2-hexen-1-ol, 1-hexanol, $(Z)$-3-hexenyl acetate and so on) were concentrated almost to the theoretical limit, about 8-12 times. The aroma components that were incorporated in the ice phase were less than $0.5 \%$, even in the worst cases $((E)-2$-hexen-1-ol). In summary, the aroma components of peach fruits were very effectively concentrated to a high degree with good yields by progressive freeze-concentration.
\end{abstract}

Keywords: progressive freeze-concentration, flavor, aroma, peach

\section{1. 緒言}

果汁飲料や果実加工食品などの製造では，製品の風 味を高めるため多くの場合に香料が添加される。香料 は天然物から抽出される「天然香料」，化学合成などに より製造される「合成香料」，両者を混合して得られる 「調合香料」に大別される [1] が，これらのなかで天然 香料には天然物の安心感があるため消費者からは最も 好まれると推測される。しかし，現在市販されている 果実天然香料の多くはレモン，ライム，グレープフルー ツなど相橘類由来のものが多く, 柑橘類以外ではイチ ゴ，リンゴ，パイナップルなどがあるもののその種類 は極めて限られる。これは相橘類では果皮を圧搾する ことにより香料の原料となる精油を容易に得られるの に対して，相橘類以外の果実ではこれが得られず，香 気成分の採取が困難なためである.

(受付 2010 年 5 月 28 日, 受理 2010 年 8 月 30 日)

1 于990-2473 山形県山形市松栄2-2-1

2 于921-8836 石川県石川郡野々市町末松一丁目 308 番地

$\dagger$ Fax: 81-23-644-3228, E-mail: tobitsukako@pref.yamagata.jp
一般に，相橘類以外の果実から産業的に香気成分を 抽出, 濃縮する際には芳香回収装置とよばれる精留塔 が用いられる。しかし, 本手法は試料の加熱処理を伴い, 香気成分の濃縮率を上げるとそれに応じて試料への加 熱量も増えるため，熱による香気成分の変質を考慮す るとあまり高濃度に濃縮することができないといわれ ている [2]．本手法で得られる香気成分水溶液の濃度は 高々 $1.5 \mathrm{~g} / \mathrm{kg}$ 程度とされる [2]. 果実から抽出した香 気成分を香料素材として利用するためにはできるだけ 高濃度に濃縮することが必要で，また香気成分の熱変性 を考慮すると濃縮操作は非加熱であることが望ましい.

これまで我々は，天然由来の香料素材として活用す ることを目的に，果実香気成分の抽出，濃縮に関する 研究を行ってきた [3-6]. 様々な濃縮方法があるなかで, 試料の加熱処理を伴わない手法である凍結濃縮法，と くに界面前進凍結濃縮法 [7-9] に着目して種々検討し てきた．界面前進凍結濃縮法は宮脇らが提唱するもの で，従来法である懸濁結晶法と比較して装置コストを 大きく低減できるとされる，前報 [6] では西洋ナシ果 実（ラ・フランス）を試験対象として，果汁を減圧蒸 
留して得られる凝縮水を界面前進凍結濃縮することに より，香気成分を効率良く濃縮できることを報告した。 本研究では，モモ果実香気成分の濃縮に界面前進凍結 濃縮法を適用し，いくつかの知見を得たので報告する.

\section{2. 実 験 方 法}

\section{1 試料}

\subsection{1 モモ果汁}

2009 年に山形県で収穫されたモモ果実（川中島白桃 $9.8 \mathrm{~kg})$ を水洗し種子を取り除いた後, 破砕機で破砕し た。これを果実搾汁用の布袋に入れ, 油圧搾汁機（KS-1 型，池田機械工業(株)）を用いて圧搾した。操作圧力は 最大で約 $50 \mathrm{~kg} / \mathrm{cm}^{2}$ とした。得られた果汁 $(4.0 \mathrm{~kg})$ を

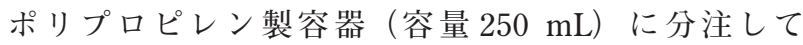
$-80^{\circ} \mathrm{C}$ で貯蔵した. 使用時に必要量を流水中で解凍した.

\subsection{2 モモ果汁減圧蒸留凝縮水}

ロータリーエバポレータ（N-1000K 型，東京理化器 械(株)）を用いて，モモ果汁（1.2 L） を減压蒸留した。 $60^{\circ} \mathrm{C}$ に保持したウオーターバスでモモ果汁を加温し, アスピレータで減圧，冷却器には氷水を循環させて約 $0^{\circ} \mathrm{C}$ に保持した。得られた凝縮水 $(860 \mathrm{~mL})$ をー $30^{\circ} \mathrm{C} て ゙$ 貯蔵し，使用時に流水中で解凍した。

\section{2 方法}

\subsection{1 モモ果汁減圧蒸留凝縮水の界面前進凍結濃縮}

富士高圧機器(株)製の円筒形試料容器（内径約 $50 \mathrm{~mm}$ ×高さ約 $180 \mathrm{~mm}$; 側面，約 $4 \mathrm{~mm}$ 厚透明アクリル樹脂 製；底面，約 $32 \mathrm{~mm}$ 厚ステンレス鋼製）に，モモ果汁 減圧蒸留凝縮水 $180 \mathrm{~mL}$ を入れた。凝縮水を擋拌 $(700$ $\mathrm{rpm})$ しながら，円筒形試料容器を冷媒 $\left(-15^{\circ} \mathrm{C}\right)$ 中に 降下 $(5 \mathrm{~mm} / \mathrm{h})$ させた。約 17 時間経過した後，凍結 せずに残った水溶液を採取した。なお，凝縮水の擋拌 にはアズワン(株)製のハイパワーミキサ SM-102 型およ び摚拌羽根 F-40 型，冷媒の冷却には東京理化器械(株製 のプロクールバス NCB-3200 型，試料容器の降下には 富士高圧機器(株)製の界面前進凍結濃縮装置を用いた。

\subsection{2 生成氷の部分融解}

2.2.1の操作で濃縮液を採取した後, 試料容器に残っ た円柱形の氷を取り出してブフナ漏斗の上に静置した. これを室温で放置し，水が融解して得られる水溶液（以 下，融解液）を 10 の画分に分けて採取した.

2.2.3 モモ果汁の分析（pH，比重，ブリックス糖度， 酸度)

$\mathrm{pH}$ の測定にはガラス電極式の $\mathrm{pH} メ ー タ （ \mathrm{~F}-22$ 型, (株堀場製作所）を用いた。比重の測定には浮ひょう式 の比重計（標準比重計，(株)東亜計器製作所）を用いた。 ブリックス糖度の測定には自動温度補正式手持屈折計 （MASTER-A1T 型，(株)アタゴ）を用いた。モモ果汁 10
$\mathrm{mL}$ の $\mathrm{pH}$ を 8.2 とするのに要する $\mathrm{N} / 10$ 水酸化ナトリ ウム水溶液の滴下量 $(\mathrm{mL})$ を酸度とし，これよりクエ ン酸換算值を算出した.

\subsection{4 モモ香気成分の分析}

試料 $1 \mathrm{~mL}$ ，塩化ナトリウム $0.4 \mathrm{~g}$ 抢よび内部標準溶 液（1％ベンジルアルコール水溶液） $100 \mu \mathrm{L}$ をガラス製 バイアル（内径約 $20 \mathrm{~mm} \times$ 高さ約 $45 \mathrm{~mm}$ ）に入れ, PTFE 被覆セプタムで密封した。これをオートサンプラ (AOC-5000 型，(株)島津製作所）で $50^{\circ} \mathrm{C}$ に保持しながら $500 \mathrm{rpm}$ で 10 分間擋找した後，ヘッドスペースガス 1 $\mathrm{mL}$ を GC（GC-17A 型，(株島津製作所）に注入した. 分析は 3 回行い平均值を求めた。

$\mathrm{GC}$ 分析条件は以下のとおり。キャリアガス; $\mathrm{He}$ $(22 \mathrm{kPa})$ ，スプリット比 ; 1 対 1 , カラム, DB-WAX（内径 $0.53 \mathrm{~mm} \times$ 長さ $30 \mathrm{~m}$, 膜厚 $0.5 \mu \mathrm{m}$, Agilent Technologies), カラム温度 ; $40^{\circ} \mathrm{C}(5 \mathrm{~min}), 40 \rightarrow 220^{\circ} \mathrm{C} \quad\left(7^{\circ} \mathrm{C} /\right.$ $\min ), 220^{\circ} \mathrm{C}(10 \mathrm{~min})$, 検出器 ; FID $\left(250^{\circ} \mathrm{C}\right)$.

\subsection{5 浸透圧測定}

試料 $2.5 \mathrm{~mL}$ をプラスチック製試験管に入れ，試料中 心部にサーミスタセンサをセットして， $-20^{\circ} \mathrm{C} て ゙$ 全体 を凍結させた後，試験管ミキサ（Iwaki TM-251）を用 いて, 室温で強く攪拌しながら, 解凍過程を測定 (Takara Thermistor D641）し，解凍曲線の屈曲点から凝固点温 度を $0.01^{\circ} \mathrm{C}$ の精度で測定し，これを浸透圧に換算した $[10,11]$.

\section{3. 結果および考察}

Table 1 に試験に用いたモモ果汁の性状を示す。川中 島白桃は糖度が高く，香りも上品な品種といわれる.

Table 2 にモモ果汁を減圧蒸留して得られた凝縮水 (以下，凝縮水)，凝縮水を界面前進凍結濃縮した濃縮 液（以下，凍結濃縮液）の主な香気成分濃度，ならび に凍結濃縮液の香気成分の濃縮倍率を示す。モモの香 気成分は $\gamma-$ ラクトン類, $\delta$-デカラクトンなどのラクト ン類の存在が特徵で，なかでも $\gamma$-デカノラクトンが多 く含まれるといわれる $[12,13]$. Table 2 に示した 10 成 分のなかでも $\gamma$-デカノラクトンの濃度が最も高く，凝 縮水で $1110 \mu \mathrm{g} / \mathrm{L}$ であった。 その他の成分では， $(E)$ -2-ヘキセン -1-オール，1-ヘキサノール， $(Z)-3-ヘ キ$

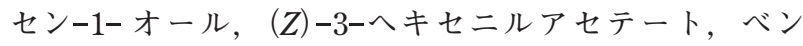
ズアルデヒドなどの濃度が高かった。これらは過去の 報告 [14-17] に打いても，一般にモモ果実に多く含ま

Table 1 Properties of peach juice.

\begin{tabular}{cccc}
\hline $\mathrm{pH}$ & $\begin{array}{c}\text { Density } \\
(\mathrm{g} / \mathrm{mL})\end{array}$ & $\begin{array}{c}\text { Brix } \\
(\%)\end{array}$ & $\begin{array}{l}\text { Acidity* } \\
(\mathrm{g} / 100 \mathrm{~g})\end{array}$ \\
\hline 4.48 & 1.053 & 12.3 & 0.22 \\
\hline
\end{tabular}

*As citric acid 
Table 2 Volatile components in distillation-condensate of peach juice, freeze-concentrate of the distillationcondensate, and their concentration rate.

\begin{tabular}{lcccc}
\hline \multirow{1}{*}{ Compound } & K. I. & \multicolumn{2}{c}{ Concentration $(\mu \mathrm{g} / \mathrm{L})^{2}$} & Concentration rate \\
\cline { 3 - 4 } & & 12.1 & 70.5 & $(\mathrm{~b} / \mathrm{a})$ \\
\hline Hexyl acetate & 1283 & 44.5 & 388 & 5.82 \\
$(Z)$-3-Hexenyl acetate & 1329 & 99.3 & 1120 & 8.71 \\
1-Hexanol & 1368 & $<10$ & 14.3 & 11.3 \\
$(E)$-3-Hexen-1-ol & 1379 & 75.2 & 730 & - \\
$(Z)-3-H e x e n-1-01$ & 1399 & 249 & 2920 & 9.70 \\
$(E)$-2-Hexen-1-ol & 1421 & 43.2 & 499 & 11.7 \\
Benzaldehyde & 1561 & $<10$ & 1220 & 11.5 \\
$\gamma$-Octanolactone & 1944 & $<10$ & 26.0 & - \\
$\beta$-Ionone & 1966 & 1110 & 9150 & - \\
$\gamma$-Decanolactone & 2176 & & & 8.21 \\
\hline
\end{tabular}

れる香気成分であるといわれている.

Table 2 に示した凝縮水の界面前進凍結濃縮試験で は, $180 \mathrm{~mL}$ の凝縮水から $15.5 \mathrm{~mL}$ の凍結濃縮液が得ら れた。 よって体積比 (180/15.5) で約 11.6 倍に濃縮さ

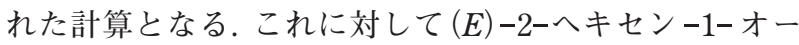
ル，ベンズアルデヒド执よび 1-へキサノールの濃縮倍 率は打よそ 11 から 12 倍， $(Z)-3-$-ヘキン -1-オール， (Z)-3-ヘキセニルアセテートおよび $\gamma$-デカノラクトン の濃縮倍率はおよそ 8 から 10 倍程度となり, 前述の計 算值（11.6 倍）と比較的近い值となった。酢酸へキシ ルの濃縮倍率は計算值の半分程度 (5.82 倍) と低かっ たが，これは酢酸へキシルの濃度が低く，試験操作中 に揮散や吸着などにより失われたためと推察された。 なお凝縮水，凍結濃縮液ともにモモ果実を想起させる 香りを有していた。参考として，Fig. 1 に凍結濃縮液の ガスクロマトグラムを示す。

Table 3 に，凝縮水の界面前進凍結濃縮操作で生成し た氷を融解させて得られた水溶液（以下，融解液）の 香気成分濃度を示す． 約 $16.4 \mathrm{~mL}$ ずつ 10 の画分に分け

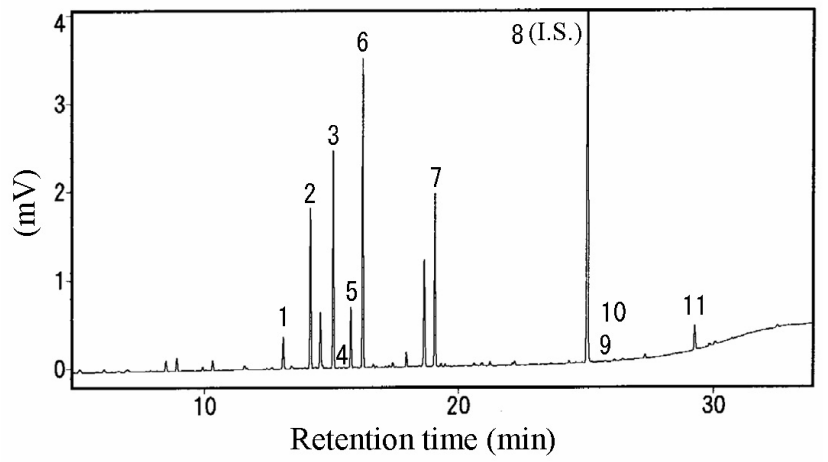

Fig. 1 GC chromatogram of freeze-concentrate of the distillation-condensate of peach juice.

1. Hexyl acetate, 2. (Z)-3-hexenyl acetate, 3. 1-hexanol, 4. (E)-3-hexen-1-ol, 5. (Z)-3-hexen-1-ol, 6. (E)-2-hexen-1ol, 7. benzaldehyde, 8. benzyl alcohol, 9. $\gamma$-octanolactone, 10 . $\beta$-ionone, 11. $\gamma$-decanolactone.
て融解液を採取し，得られた順に Fraction number 1〜 10 とした。

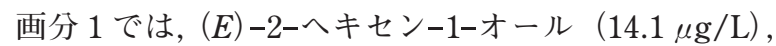
(Z) -3-ヘキセニルアセテート $(10 \mu \mathrm{g} / \mathrm{L}$ 未満 $), 1$-ヘキ サノール $(10 \mu \mathrm{g} / \mathrm{L}$ 末満 $)$ およびベンズアルデヒド $(10 \mu \mathrm{g} / \mathrm{L}$ 未満 $)$ の 4 成分が少量検出されたが他の 6 成 分は検出されず，画分 2 から画分 10 では全ての成分が 検出されなかった。画分 1 に含まれる $(E)-2-へ$ キン -1-オールの量は，濃縮前の凝縮水（180 mL 中）に含 まれる量の約 $0.5 \%$ であることから，本濃縮操作により 水に取り込まれる香気成分はごくわずかであることが わかった。これまでの報告では，界面前進凍結濃縮試 験における濃縮倍率は数倍程度のものが多いが $[18$, 19]，本研究では多くの成分を 10 倍前後に濃縮できた のに加えて，水に取り込まれた溶質量も少なく極めて 効率良く濃縮できた。

Table 4 に試験に用いたモモ果汁と凝縮水の浸透圧を 示す。凝縮水の浸透圧は低く，果汁の打よそ 18 分の 1 であった。これはモモ果汁の溶質の大部分を占める糖 類や有機酸類が減圧蒸留により分離され，凝縮水には

Table 3 Volatile components in partially-melt fraction of ice phase formed in progressive freeze-concentration of the distillation-condensate of peach juice.

\begin{tabular}{|c|c|c|c|}
\hline \multirow[t]{2}{*}{ Compound } & \multirow[t]{2}{*}{ K. I. } & \multicolumn{2}{|c|}{ Fraction number } \\
\hline & & 1 & $2 \sim 10$ \\
\hline Hexyl acetate & 1283 & N.D. & N.D. \\
\hline (Z)-3-Hexenyl acetate & 1329 & $<10$ & N.D. \\
\hline 1-Hexanol & 1368 & $<10$ & N.D. \\
\hline (E)-3-Hexen-1-ol & 1379 & N.D. & N.D. \\
\hline (Z)-3-Hexen-1-ol & 1399 & N.D. & N.D. \\
\hline (E)-2-Hexen-1-ol & 1421 & 14.1 & N.D. \\
\hline Benzaldehyde & 1561 & $<10$ & N.D. \\
\hline$\gamma$-Octanolactone & 1944 & N.D. & N.D. \\
\hline$\beta$-Ionone & 1966 & N.D. & N.D. \\
\hline$\gamma$-Decanolactone & 2176 & N.D. & N.D. \\
\hline
\end{tabular}

$\mu \mathrm{g} / \mathrm{L}$ 
Table 4 Osmotic pressure of peach juice and distillationcondensate of peach juice.

\begin{tabular}{lcc}
\hline & Juice & Distillation-condensate \\
\hline $\begin{array}{l}\text { Osmotic } \\
\text { pressure }(\mathrm{MPa})\end{array}$ & 1.28 & $7.19 \times 10^{-2}$ \\
\hline
\end{tabular}

含まれないためである.

界面前進凍結濃縮では，試料溶液の浸透圧が高いほ ど氷晶層に溶質が取り込まれやすいことが知られてい る [20,21]. 本研究では凝縮水の浸透圧が低いため，溶 質が氷にほとんど取り込まれることなく効率良く濃縮 されたものと考えられる。過去に我々は, 西洋ナシ (ラ・ フランス）を試験対象として同様の試験を行ったが, 凝縮水を約 12 倍濃縮したときに氷に取り込まれた香気 成分量は多いものでも投入量の $3 \%$ 未満となり，本研究 結果と同様に効率良く濃縮された [6]. 以上のことから, 凝縮水のように浸透圧の低い試料の濃縮に打いて界面 前進凍結濃縮は極めて有効な手法であると考えられた。

\section{4. 結論}

凍結濃縮は加熱を伴わないマイルドな手法であるた め，香気成分など熱に不安定な物質の濃縮に適してい ると考えられる。本論文では，界面前進凍結濃縮法に よるモ乇果実香気成分水溶液（モモ果汁の減圧蒸留凝 縮水)の濃縮を試み，以下の知見を得た.

モモ果汁の減圧蒸留凝縮水（180 mL） を界面前進凍 結濃縮して濃縮液（15.5 mL）を得た（体積比で約 11.6 倍濃縮)。この操作により，多くのモモ果実香気成分が

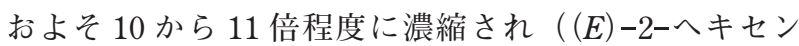
-1-オール，11.7 倍 ; ベンズアルデヒド， 11.5 倍 ; 1-へ キサノール，11.3 倍; $(Z)$-3-ヘキセン-1-オール, 9.70 倍など）理論值に近い濃縮倍率となった。一方，界面 前進凍結濃縮操作で生成した水に取り込まれた香気成 分の量は，最も多いものでも投入量の約 $0.5 \%$ であった ( $(E)-2-$ - キン-1-オール)，界面前進凍結濃縮法によ り，モモ果実香気成分は効率良く濃縮されることがわ かった.

\section{謝 辞}

本研究は平成 21 年度農林水産省委託事業（新たな農 林水産政策を推進する実用技術開発事業，研究課題番 号：2038）の委託を受けて行った。記して謝意を表す。

\section{引 用 文 献}

1) S. Shimizu, H. Kakuta, M. Makino; "Food and the Flavor (Syokuhin to kaori)”, Kohrin, Tokyo, Japan, 2004, pp.
117-120.

2) Glico Dairy Products Company, Limited; "Method of making highly concentrated aroma components of fruit, and the foods mixed them (kazitsu houkou seibun no kounousyukueki no seizou houhou oyobi gaiseizou houhou niyori erareta kounousyukueki wo haigoushita syokuhin)”. Koukai Tokkyo kouhou, Heisei 8-215 (1996).

3) K. Tobitsuka, Y. Ajiki, Y. Nouchi, Y. Hayakawa, Y. Kamiya, O, Miyawaki; "Progressive freeze-concentration of aroma component aqueous solution (kaimenzensin touketsu nousyukuhou niyoru koukiseibun suiyoueki no nousyuku)". Nippon syokuhin kougakukai taikai kouenyousi, 23 (2009).

4) K. Tobitsuka, Y. Ajiki, Y. Nouchi, O, Miyawaki; "Progressive freeze-concentration of aroma components of La France pear (kaimenzensin touketsu nousyukuhou niyoru rahuransu koukiseibun no nousyuku)”. Nippon syokuhin kougakukai taikai kouenyousi, 24 (2009).

5) A. Yuba, K. Watabe, K. Tobitsuka, O. Miyawaki; "Progressive freeze-concentration of La France pear condensed water (kaimenzensin touketsu nousyukuhou niyoru rahuransu gyousyukueki no nousyuku)”. Nippon syokuhin kougakukai taikai kouenyousi, 103 (2009).

6) K. Tobitsuka, Y. Ajiki, Y. Nouchi, O, Miyawaki; "Progressive freeze-concentration of aroma components of La France pear” (in Japanese). Japan J. Food. Eng., 11, 31-36 (2010).

7) O. Miyawaki; "Recent progress in freeze concentration" (in Japanese). Refrigeration, 77, 31-37 (2002).

8) O. Miyawaki; "Freeze-concentration and membraneconcentration" (in Japanese). Food Chemicals, 4, 69-73 (2003).

9) O. Miyawaki; "Engineering approach for food processing at low temperatures" (in Japanese). Japan J. Food Eng. technol., 6, 221-228 (2005).

10) O. Miyawaki, A. Saito, T. Matsuo, K. Nakamura, Activity and activity coefficient of water in aqueous solutions and their relationships with solution structure parameters. Biosci. Biotech. Biochem., 61, 466-469 (1997).

11) F. Dumont, P. A. Marechal, P. Gervais, Influence of cooling rate on Saccharomyces cerevisiae destruction during freezing: unexpected viability at ultra-rapid cooling rates. Cryobiology, 46, 33-42 (2003).

12) M. Fujimaki, T. Hattori, K. Hayashi, S. Arai; "Cyclopedia of Spice (Kouryou no Jiten)”, Asakurasyoten, Tokyo, Japan, 1991, p. 142

13) Japanese spice society; "Encyclopedia of Smell (Kaori no Hyakkajiten)”, Asakurasyoten, Tokyo, Japan, 2006, pp. 592-594.

14) N. Kakiuchi, A. Ohmiya; Changes in the composition and content of volatile constituents in peach fruits in relation 
to maturity at harvest and artificial ripening. J. Japan. Soc. Hort. Sci., 60, 209-216 (1991).

15) G. R. Takeoka, R. A. Flath, M. Guntert, W. Jennings; Nectarine volatiles: Vacuum steam distillation versus headspace sampling. J. Agric. Food Chem., 36, 553-560 (1988).

16) N. Narain, T. C. Y. Hsieh, C. E. Johnson; Dynamic headspace concentration and gas chromatography of volatile flavor components in peach. J. Food Sci., 55, 1303-1307 (1990).

17) R. J. Horvat, G. W. Chapman, Jr., J. A. Robertson, F I. Meredith, R. Scorza, A. M. Callahan, P. Morgens; Comparison of the volatile compounds from several commercial peach cultivars. J. Agric. Food Chem., 38, 234-237 (1990)

18) O. Miyawaki, L. Liu, Y. Shirai, S. Sakashita, K. Kagitani; Tubular ice system for scale-up of progressive freezeconcentration. J. Food Eng., 69, 107-113 (2005).

19) A. Yuba, O. Miyawaki; "Application of progressive freeze-concentration in salt manufacture from deepocean water (Kaiyousinsousui karano seien niokeru kaimenzensin touketsu nousyukuhou no ouyou)". Nippon nougeikagakukai taikai kouenyousi, 69 (2009).

20) X. Gu, M. Watanabe, T. Suzuki, O. Miyawaki; Limiting partition coefficient in a tubular ice system for progressive freeze-concentration. Food Sci. Technol. Res., 14, 249-252 (2008).

21) X. Gu, T. Suzuki, O. Miyawaki; Limiting partition coefficient in progressive freeze-concentration. J. Food Sci., 70, 546-551 (2005).

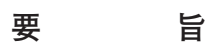

凍結濃縮は加熱を伴わないマイルドな濃縮手法であ るため，香気成分など熱に不安定な物質の濃縮に適し ている。そこで我々は界面前進凍結濃縮法による，乇 モ香気成分の濃縮を試みた。

モモ果汁を減圧蒸留してモモ香気成分を含む凝縮水 を採取した。得られた凝縮水を界面前進凍結濃縮し, モモ香気成分を濃縮した。凝縮水を体積比で 11.6 倍濃 縮したところ，主なモモ香気成分（ $\gamma$-デカノラクトン,

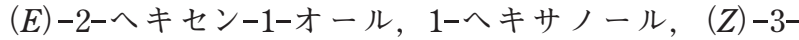
ヘキセニルアセテート，その他）の濃度は，扎よそ8〜 12 倍前後となり，比較的理論值に近い濃縮率となった。 一方，界面前進凍結濃縮操作で生成した水に取り込ま れた香気成分量は，最も多いものでも投入量の約 $0.5 \%$ であった（(E)-2-ヘキセン-1-オール）。界面前進凍結 濃縮法により，モモ香気成分は効率良く濃縮されるこ とがわかった。 